\title{
Achilles Tendon Rupture with Isolated Medial Malleolar Fracture in Ipsilateral Ankle: A Case Report
}

\author{
Fatih Türkmensoy ${ }^{1}$, Ismail Türkmen ${ }^{1}$, Yalçın Turhan ${ }^{2}$, Korhan Özkan $^{1}$, Mehmet Akif Akçal ${ }^{3}$ \\ ${ }^{1}$ Department of Orthopaedics and Traumatology, Göztepe Training and Research Hospital, İstanbul Medeniyet University, İstanbul, \\ Turkey; ${ }^{2}$ Department of Orthopaedics and Traumatology, Düzce Atatürk State Hospital, Düzce, Turkey; ${ }^{3}$ Department of Ortho- \\ paedics and Traumatology, Kilis State Hospital, Kilis, Turkey. \\ Email: turkmensoyfatih@yahoo.com,dr.ismailturkmen@gmail.com, yturhan_2000@yahoo.com, korhanozkan76@gmail.com, \\ mehmetakifakcal@yahoo.com
}

Received July $15^{\text {th }}, 2013$; revised August $15^{\text {th }}, 2013$; accepted August $29^{\text {th }}, 2013$

Copyright (C) 2013 Fatih Türkmensoy et al. This is an open access article distributed under the Creative Commons Attribution License, which permits unrestricted use, distribution, and reproduction in any medium, provided the original work is properly cited.

\begin{abstract}
Achilles tendon ruptures and malleol fractures are commonly seen injuries in orthopaedic and traumatology practice, but what is rare is their concomitant. In this report, we aimed to present a rare case of a patient who has isolated medial malleolar fracture and achilles tendon rupture in ipsilateral ankle after an ankle sprain due to a fall from stairs and mechanism of injury.
\end{abstract}

Keywords: Achilles Tendon Rupture and Malleol Fracture; Injury Mechanism

\section{Introduction}

Achilles tendon is the strongest tendon in the human body which occurs with incorporation of M. Gastrocnemius and M. Soleus tendons. Acute rupture of this tendon is one of the commonest injuries in adults [1].

Malleol fractures are also frequently seen in orthopaedics and traumatology practice, which usually occur after ankle sprain [2]. Medial malleol fractures are sometimes seen as isolated, but they are often together with fractures of lateral and/or posterior malleolus. Although acute Achilles tendon rupture and medial malleolar fractures are relatively frequent, the concomitant association of those two injuries in ipsilateral ankle is rare with only six single cases having been reported in the English speaking literature [2].

In this report, we aimed to present a patient with acute Achilles tendon rupture and isolated medial malleol fracture and tried to present the possible injury mechanism.

\section{Case Presentation}

A 42 years old male who fell down from stairs was seen in our emergency unit with pain and tenderness over his right ankle joint. He was wearing a shoe and his injury happened while he was going up the stairs. He inverted his right foot and fell down four stairs. He had heard a "pop-up" sound before inverting his ankle.
In his detailed physicial examination the pain was localized posterior and medial aspect of his ankle joint and a three centimetres gap was palpable four centimetres proximal to the distal insertion of his Achilles tendon.

The patient could not plantar flexion his foot actively and the Thompson test was positive. His ankle roentgenograpies and CT images revealed a non displaced medial malleolar fracture (Figure 1) while MRI of the same ankle revealed an Achilles tendon rupture (Figure 2). He was hospitalized with the acute Achilles tendon rupture and isolated medial malleolar fracture in his ipsilateral ankle.

The patient underwent surgery next day. Prone position was choosen and thigh tourniquet was used to

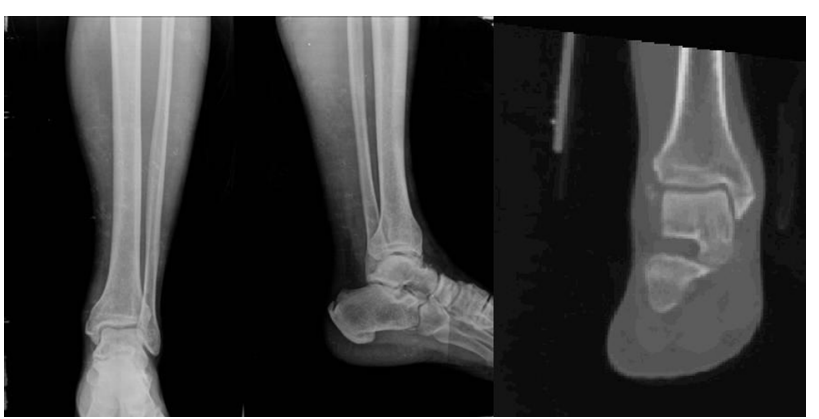

Figure 1. Preoperative X-ray and CT of the right ankle. 
provide a bloodless field. Under fluroscopic guidence medial malleol fracture was fixed by a malleolar screw percutaneously first (Figure 3). Then, repair of Achilles tendon was made. The tendon exposed using medial approach with an end-to-end repaired using the well known Krakow technique and it was strengthened with the circumferential surgery knots. Subcutaneus fat closed with absorbable sutures and to close the skin non-absorbable sutures were used. After the procedure a long-leg cast was applied with slightly equines position. He was encouraged to mobilise with crutches when he reached his room. At his third postoperative day he was discharged after his wound was controlled.

Twelve days later the sutures was removed and one month later his cast was changed with short-leg cast in naturel position and he was encouraged to full-weightbear on his ankle. The cast was removed on the second month of the surgery and mobilised under directions of physiotherapist. He was walking without crutches, but there was two heel height on operation side. In the third mounth he could walk with full-weight-bear. In the eight mounth follow up he was asymptomatic with full range of active-passive ankle motion and fully weight bearing, so he was discharged from follow-up.

\section{Discussion}

Acute Achilles tendon rupture is the most common tendon injury in adults, especially in man. It occurs fre-

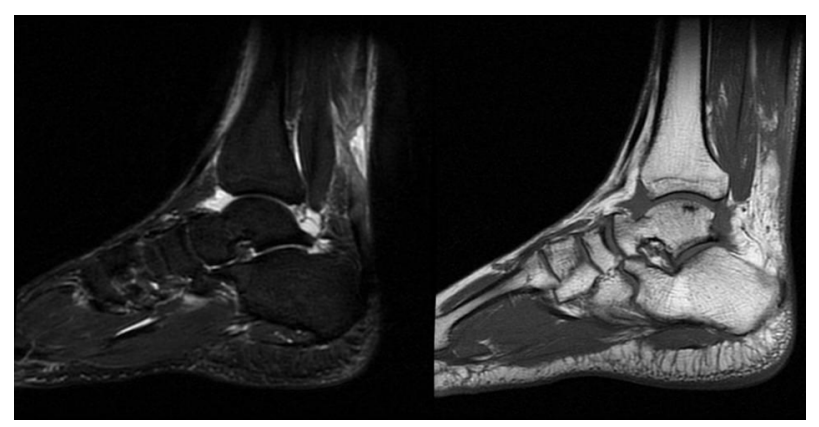

Figure 2. Preoperative MRI of the right ankle.

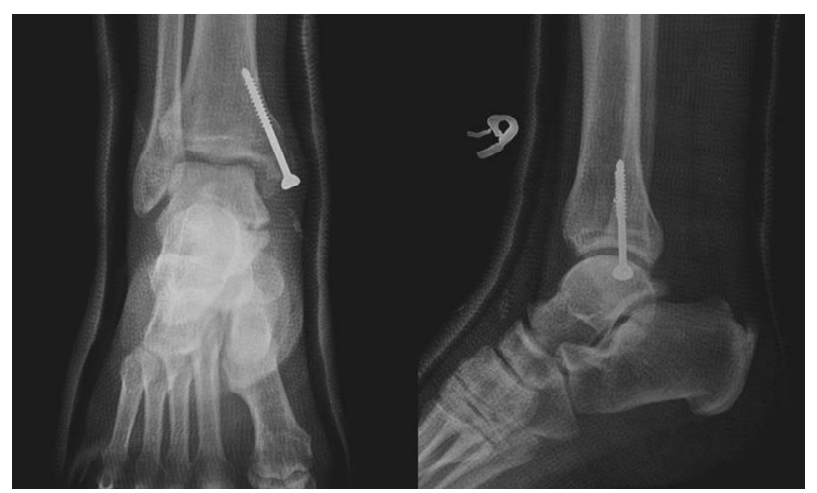

Figure 3. Postoperative $\mathrm{X}$-ray of the right ankle. quently in sports action. Treatments of this condition include surgery or non-surgery treatment [3]. Open reduction and primary repair of tendon are gold Standard and various surgical techniques have been described [4]. Combined with medial malleolar fracture, acute Achilles tendon is rare and injury mechanism generally consists of suddenly loading energy to ankle and forefoot [2]. Six cases have been reported in the literature up to this date, and the causes of these concominant injuries were motor vehicle accident in one case, sports injuries in two cases and fall or false step on stairs or ladder in three cases. Detailed history of these patients revealed that injuries consist of hyperextansion of forefoot which might cause Achilles tendon rupture and then hindfoot inversion with resultant medial malleolar fracture.

The mechanism of injury in our case was consistent with the previus reports of concominant Achilles tendon rupture with isolated medial malleolar fracture. Assal at al recommended that patients with a supination adduction ankle injury should have an examination of Achilles tendon integrity although this is also true for eversion injuries [5]. Lugger at al found 5.3\% insidance of medial malleolar fracture in Alpine skiers who sustained an Achilles tendon rupture due to eversion type injuries [6]. Six cases have been reported in the literature up to this date, but we belive that its insidance is more than that.

\section{Conclusion}

Routine antero-posterior and lateral X-rays should be taken in acute Achilles tendon injuries to identify bone lesion and in ankle injuries systemic examination should be made to show the soft tissue condition for acute Achilles tendon rupture, especially if injury mechanism includes hindfoot inversion and hyperextension of forefoot.

\section{REFERENCES}

[1] J. Maquirriain, “Achilles Tendon Rupture: Avoiding Tendon Lengthening during Surgical Repair and Rehabilitation," Yale Journal of Biology and Medicine, Vol. 84, No. 3, 2011, pp. 289-300.

[2] N. Maffulli and P. J. Richards, "Subcutaneous Rupture of the Achilles Tendon and Ipsilateral Fracture of the Medial Malleolus," BMC Musculoskeletal Disorders, Vol. 7, No. 59, 2006, pp. 1-5.

[3] H. M. Zhao, G. R. Yu, Y. F. Yang, J. Q. Zhou and A. Aubeeluck, "Outcomes and Complications of Operative versus Non-Operative Treatment of Acute Achilles Tendon Rupture: A Meta-Analysis," Chinese Medical Journal, Vol. 124, No. 23, 2011, pp. 4050-4055.

[4] Z. Feldbrin, D. Hendel, A. Lipkin, D. Zin and L. Schorr, "Achilles Tendon Rupture and Our Experience with The Achillon Device," Israel Medical Association Jornal, Vol. 12, No. 10, 2010, pp. 609-612.

[5] M. Assal, R. Stern and R. Peter, "Fracture of the Ankle 
Associated with Rupture of the Achilles Tendon: Case Report and Review of the Literature," Journal of Orthopaedic Trauma, Vol. 16, No. 5, 2002, pp. 358-361. doi:10.1097/00005131-200205000-00013

[6] L. J. Lugger, R. Margreiter and W. Glötzer, "Rupture of the Achilles Tendon and Eversion Fracture of the Inner Malleolus-A Typically Combined Injury in Alpin Skiing," Zentralblad für Chirurgie, Vol. 102, No. 21, 1977, pp. 1320-1323. 